\title{
Circadian analysis of myocardial infarction incidence in an Argentine and Uruguayan population
}

\author{
Carlos E D'Negri ${ }^{1}$, Leonardo Nicola-Siri ${ }^{1,2,3}$, Daniel E Vigo ${ }^{1,4}$, Luis A Girotti ${ }^{2}$ \\ and Daniel P Cardinali*1,4
}

\author{
Address: ${ }^{1}$ Consejo Nacional de Investigaciones Científicas y Técnicas, Argentina, ${ }^{2}$ División de Cardiología, Hospital Ramos Mejía, Buenos Aires, \\ Argentina, ${ }^{3}$ Laboratorio de Bioelectricidad, Escuela de Ingeniería - Bioingeniería, Universidad Nacional de Entre Ríos, Argentina and \\ ${ }^{4}$ Departamento de Fisiología, Facultad de Medicina, Universidad de Buenos Aires, Argentina \\ Email: Carlos E D'Negri - cnegri@fibertel.com.ar; Leonardo Nicola-Siri - nicolasirileo@yahoo.com; Daniel E Vigo - dvigo@fmed.uba.ar; \\ Luis A Girotti - lgirotti@gema.org.ar; Daniel P Cardinali* - cardinal@mail.retina.ar \\ * Corresponding author
}

Published: 09 January 2006

BMC Cardiovascular Disorders 2006, 6:1 doi:10.1186/147|-226|-6-1

This article is available from: http://www.biomedcentral.com/I47I-226I/6/I

(c) 2006 D'Negri et al; licensee BioMed Central Ltd.

This is an Open Access article distributed under the terms of the Creative Commons Attribution License (http://creativecommons.org/licenses/by/2.0), which permits unrestricted use, distribution, and reproduction in any medium, provided the original work is properly cited.
Received: 24 August 2005

Accepted: 09 January 2006

\begin{abstract}
Background: The occurrence of variations in the spectrum of cardiovascular disease between different regions of the world and ethnic groups have been the subject of great interest. This study report the 24-h variation of myocardial infarction (MI) occurrence in patients recruited from CCU located in Argentina and Uruguay.

Methods: A cohort of 1063 patients admitted to the CCU within $24 \mathrm{~h}$ of the onset of symptoms of an acute $\mathrm{MI}$ was examined. $\mathrm{MI}$ incidence along the day was computed in I h-intervals.

Results: A minimal Ml incidence between 03:00 and 07:00 $\mathrm{h}$ and the occurrence of a first maximum between 08:00 and 12:00 $\mathrm{h}$ and a second maximum between 15:00 and 22:00 $\mathrm{h}$ were verified. The best fit curve was a $24 \mathrm{~h}$ cosinor (acrophase 19:00 h, accounting for $63 \%$ of variance) together with a symmetrical gaussian bell (maximum at $\sim 10: 00 \mathrm{~h}$, accounting for $37 \%$ of variance). A similar picture was observed for $\mathrm{MI}$ frequencies among different excluding subgroups (older or younger than 70 years; with or without previous symptoms; diabetics or non diabetics; $Q$ wave- or non- $Q$ wave-type Ml; anterior or inferior Ml location). Proportion between cosinor and gaussian probabilities was maintained among most subgroups except for older patients who had more $\mathrm{Ml}$ at the afternoon and patients with previous symptoms who were equally distributed among the morning and afternoon maxima.
\end{abstract}

Conclusion: The results support the existence of two maxima (at morning and afternoon hours) in $\mathrm{MI}$ incidence in the Argentine and Uruguayan population.

\section{Background}

More than 50 years ago, Pell and D'Alonzo first demonstrated the existence of a peak in the morning hours in a study of acute myocardial infarction (MI) in a large industrial population [1]. Subsequent population studies showed a non-uniform circadian distribution of events with a morning peak [2-11] and sometimes a smaller afternoon peak $[3,4,12]$. A double-peak distribution of MI was reported more than a decade ago $[13,14]$ with fatal infarctions being prevalent in the morning span [15]. 
Table I: Patient comorbidities and concomitant therapy

\begin{tabular}{ll}
\hline Comorbidity & \\
\hline Hypertension & $541(53.7 \%)$ \\
Diabetes & $174(16.4 \%)$ \\
Tobacco & $475(44.7 \%)$ \\
Previous Myocardial Infarction & $158(14.9 \%)$ \\
\hline Concomitant Therapy & \\
\hline Beta blocker & \\
ACE inhibitor & $679(63.9 \%)$ \\
Amiodarone & $372(35 \%)$ \\
Thrombolytic & $542(51 \%)$ \\
PTCA & $652(61.3 \%)$ \\
CABG & $130(12.2 \%)$ \\
\hline
\end{tabular}

Shown are the number of patients and percentage. For further information on the population studied see [27]

Moreover, a temporal pattern characterized by a same double-peak curve has been found for both ischemic and hemorrhagic stroke [16-18], rupture/dissection of aortic aneurysms [19] and peripheral artery embolization [20].

The occurrence of variations in the spectrum of cardiovascular disease between different regions of the world and ethnic groups have been the subject of great interest [21$25]$. There are also considerable variations in the prevalence of cardiovascular risk factors (smoking, hypertension, hyperlipidemia and diabetes) among different ethnic groups [26]. In a recent paper examining whether ethnicity influences the circadian pattern of acute MI, a significantly higher number of acute MI onsets occurring between midnight and noon was observed in British Caucasians and Indo-Asians, whereas in Mediterranean Caucasians most of the acute MI events happened between noon and midnight [25].

This prompted us to examine the MI incidence along the day in the data obtained from GEMICA Study database, a prospective, multicenter, randomized, placebo-controlled, double blind, trial design to assess the effect of amiodarone on mortality after MI in an Argentine and Uruguayan population. The results of the GEMICA study were published elsewhere [27].

\section{Methods}

\section{Population examined}

GEMICA was launched in March 1994 and completed in July 1995 [27]. Patients were screened and recruited from 63 CCU in Argentina, and from 2 in Uruguay. The protocol was reviewed and approved by an independent external Safety and Monitoring Board of the Study as well as by the local Institutional Ethics Committee of each participating center.
Every patient who was hospitalized within the first $24 \mathrm{~h}$ after the onset of MI was screened. Diagnosis of infarction was based on the confirmation of two out of the three accepted criteria: i) prolonged (longer than $30 \mathrm{~min}$ ) typical chest pain not responding to nitroglycerin, ii) sustained ST segment changes and/or appearance of new Q waves; iii) doubling of the blood creatine-phosphokinase normal value. Table 1 summarizes comorbidities and concomitant therapy in the sample of patients examined. Criteria for eligibility of patients were detailed elsewhere [27].

\section{Timing of Ml onset}

The time each patient had suffered his/her MI was recorded up to within $\pm 0.5 \mathrm{~h}$ by interrogation of the patients or of their close relatives. MI incidence along the day was analyzed on total population and after dividing the population in several mutually excluding subgroups, as follows: (i) older than 70 years, 70 or less years; (ii) with or without previous symptoms; (iii) diabetics or non diabetics; (iv) Q wave- or non-Q wave-type MI; (v) anterior or inferior MI location.

To quantify the time dependence of MI incidence, the 24 $\mathrm{h}$ period was divided into $1 \mathrm{~h}$-intervals. Observed cases of MI onset in each time interval were expressed as percent incidence per hour $(\% / \mathrm{h})$ after normalizing the data by dividing the observed cases by $\mathrm{N}$ (the number of patients in total population or in each subgroup).

\section{Statistical analysis}

Periodicity in occurrence of MI episodes along the day was assessed by comparing the distribution of MI incidence against a theoretical uniform distribution. The total population, as well as every subgroup, was separately analyzed. Differences in periodicity between each pair of mutually excluding subgroups were analyzed by using Chi-square test on $2 \times 24$ contingency tables.

Least squares regression analysis on $\mathrm{MI}$ incidence was performed for the total population and for every subgroup, using the following fitting function for the probability density $\mathbf{y}(\mathbf{t})(\% / \mathbf{h})$ :

$$
\begin{aligned}
& \mathrm{y}(\mathrm{t})=\mathrm{A}+\mathrm{B}^{*} \cos \left(\omega_{24} *\left(\mathrm{t}-\mathrm{t}_{\text {acrophase }}\right)\right)+\left(\mathrm{C} /\left((2 * \Pi)^{1 / 2} * \sigma\right)\right) \\
& * \exp -\left(\left(\mathrm{t}-\mathrm{t}_{\mathrm{m}}\right)^{2} /\left(2^{*} \sigma^{2}\right)\right)
\end{aligned}
$$

The first component, $\mathrm{A}+\mathrm{B} * \cos \left(\omega_{24} *\left(\mathrm{t}-\mathrm{t}_{\text {acrophase }}\right)\right)$ is a cosinor function, i.e. a constant A $(\% / \mathrm{h})$ plus a harmonic oscillation around A with amplitude B $(\% / \mathrm{h})$, period $2 *$ $\Pi / \omega_{24}=24 \mathrm{~h}$ and maximum at the acrophase $t_{\text {acrophase }}$ (hh:mm). By integrating over $24 \mathrm{~h}$, the probability of cosinor component $(\%)$ resulted in $\mathrm{A}(\% / \mathrm{h})$ times $24 \mathrm{~h}$. The second component in [1] is a normal probability density function (gaussian) with $\mathrm{t}_{\mathrm{m}}$ (hh:mm) as mean value and 
$\sigma(\mathrm{hh}: \mathrm{mm})$ as SD. Gauss distribution was scaled to obtain $\mathrm{C}(\%)$ for gaussian component.

Being $y(t)$ a sum of probability densities, a fitting procedure was imposed to reject any negative values for every component and to comply with the normalization constraint $\mathrm{A} * 24 \mathrm{~h}+\mathrm{C}=100 \%$. Fitted constants were expressed as mean \pm SEM. Goodness of fit was checked through the correlation coefficient $\mathbf{r}$. A minimum value of $0.7(70 \%)$ was set to accept a fit. The temporal constants $\mathrm{t}_{\text {acrophase }} \mathrm{t}_{\mathrm{m}}$, and $\sigma$ were compared between mutually excluding subgroups, and also for every subgroup against total population. Differences between means $\left(m_{i}-m_{k}\right)$ were analyzed under the assumption of means being independent and normally distributed. On each case, the adimentional variable $\mathrm{z}=\left(\mathrm{m}_{\mathrm{i}}-\mathrm{m}_{\mathrm{k}}\right) /\left(\mathrm{se}_{\mathrm{i}}{ }^{2}+\mathrm{se}_{\mathrm{k}}{ }^{2}\right)^{1 / 2}$ was calculated, and the two-tailed $\mathrm{p}(\mathrm{z})$ value was obtained from a normal probability table.

Total probabilities for cosinor and gaussian components were not independent values. In consequence, differences between $\mathrm{A} * 24 \mathrm{~h}$ and $\mathrm{C}$ were analyzed for every subgroup, and also in the total population, by comparison against the half probability value 0.5 (i.e., 50\%). A test of differences between two means modified for one-tailed $\mathrm{p}(\mathrm{z})$, was used. Differences were considered non-significant if $\mathrm{p}$ $\geq 0.05$.

\section{Results}

The group of 1063 patients was analyzed as a total population and after division in excluding subgroups as described in Methods. Figure 1-a depicts the fitted curve $y(t)$ superimposed to the observed hourly MI percentage. Inspection of data indicates minimal MI incidence between 03:00 and 07:00 $\mathrm{h}$ and the occurrence of a first peak between 08:00 and 12:00 $\mathrm{h}$ and a second peak between 15:00 and 22:00 h. This second peak occurred about $12 \mathrm{~h}$ after the minimal MI incidence; thus, a $24 \mathrm{~h}$ cosinor fitting was consistent with this observation. In addition, the morning maximum (between 08:00 and $12: 00 \mathrm{~h}$ ) resembles a symmetrical bell located over the rising flank of the cosinor curve; therefore, a gaussian component was added to the fitting function.

The bimodal distribution adopted relied on the existence of significant differences between morning and evening maxima and the minima observed before sunrise and at early afternoon. For the intervals 02:00 - 07:00 h and 08:00 - 12:00 h, each hourly MI incidence differed by more than 1 SD from daily mean $(4 \pm 2) \% / h$. In the case of the 13:00 - 24:00 $\mathrm{h}$ interval, mean hourly $\mathrm{MI}$ incidence was $4.4 \pm 0.9 \% / \mathrm{h}$, with values at 15:00, 16:00 and 19:00 $\mathrm{h}$ differing by $>1 \mathrm{SD}$ from the mean. This supported the existence of a minimum at 13:00 - 15:00 $\mathrm{h}$ and a maxi- mum at 16:00 - 20:00 h, significantly above random noise

Figure 1-b shows the cosinor and gaussian components of the same population, as well as $\mathbf{y}(\mathbf{t})$, to illustrate the contribution of each parameter in fitting the function. Overall, the fitted function accounted for $84.6 \%$ of variance. Amplitude values for the cosinor component were $\mathrm{A}=$ $(2.6 \pm 0.3) \% / \mathrm{h}$ and $\mathrm{B}=(2.3 \pm 0.4) \% / \mathrm{h}$ with an acrophase ( $\mathrm{t}_{\text {acrophase }}$ ) of $18.8 \pm 0.6 \mathrm{~h}$ (i.e., 18:49 \pm 0:25 h). Integration over $24 \mathrm{~h}$ yielded a probability of $63 \pm 7 \%$ for the cosinor component (Fig. 1-b). The gaussian component exhibited a maximum $\left(\mathrm{t}_{\mathrm{m}}\right)$ at $9.9 \pm 0.2 \mathrm{~h}$ (i.e., 09:52 $\pm 0: 14 \mathrm{~h}$ ) with a standard deviation $(\sigma)$ of $2.0 \pm 0.3 \mathrm{~h}$. The probability of the gaussian component was $37 \pm 7 \%$.

When the analysis depicted in Fig. 1 was applied to MI incidence for the several excluding subgroups examined, a similar picture to the total population was obtained. Maxima in MI incidence were found at the morning $(08: 00-13: 00 \mathrm{~h})$ and at evening $(\sim 18: 00 \mathrm{~h})$ with a nadir at 02:00 - 07:00 $\mathrm{h}$ and secondary minima at 13:00 15:00 h. For every studied subgroup a $24 \mathrm{~h}$ cosinor plus a gaussian function described adequately the observed values. This is summarized in Additional file 1 and Fig. 2, in which MI probability values for the total population and for the excluding subgroups are shown. The correlation coefficients ranged from 0.79 to 0.92 and curve fitting explained $62-85 \%$ of the observed variance. For the total population the probability of cosinor component $\left(\mathrm{A}^{*} 24\right.$ h) was significantly higher $(63 \pm 7 \%)$ than that of the gaussian one $(37 \pm 7 \%, \mathrm{p}<0.024)$ (Additional file 1 and Fig. 2). When total population was divided into excluding subgroups, proportion between probabilities (roughly 60 $\%$ vs. $40 \%$ ) was maintained among most subgroups (p < 0.01 to $\mathrm{p}<0.0001$ ) except for older patients in which the difference between cosinor and gaussian was the highest ( $83 \pm 7 \%$ and $17 \pm 7 \%$ respectively, $\mathrm{p}<0.00001$ ) (Additional file 1 and Fig. 3 ) and patients with previous symptoms whose cosinor and gaussian fitting resulted equally probable (Fig. 4).

The acrophase of the cosinor component occurred between 17:25 and 19:10 $\mathrm{h}$ in the total population and in the excluding subgroups while gaussian maximum was at 10:00 h with a SD of $\pm 2 \mathrm{~h}$. Differences in these parameters between each pair of excluding subpopulations or against total population were non-significant.

\section{Discussion}

Almost all cardiovascular events exhibit a pronounced circadian rhythm, with higher frequencies in the morning when patients wake up, resume upright posture and begin activities, and a relatively lower risk during sleep. These circadian rhythms, although anchored genetically, are 

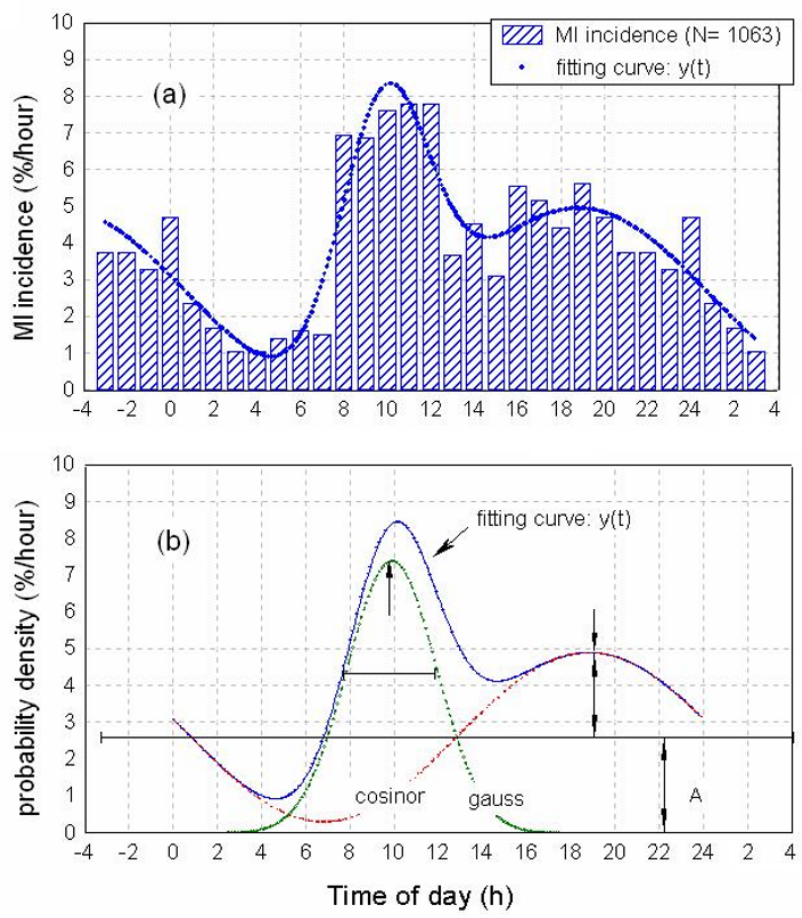

Figure I

Circadian periodicity in $\mathrm{MI}$ incidence in the population examined. Upper panel (a): Bars indicate $M I$ incidence $(\% / h)$ values, calculated as ( $100 *$ MI's per hour/total N). Curve fitting = cosinor + Gaussian for $\mathrm{n}=24$ time points was calculated as described in Methods. Values for 21:00 - 24:00 h (left) and 0l:00 - 03:00 h (right) are duplicated to illustrate fitting function. Lower panel (b): Probability density functions $(\% / \mathrm{h})$ for $\mathrm{MI}$ incidence in total population. Cosinor and gaussian components are shown separately to illustrate the contribution of each parameter in fitting the function $y(t)$.

synchronized and maintain certain phase relationships to external factors, especially the sleep portion of the lightdark schedule $[28,29]$. Such predictable-in-time differences in the physiological status of the cardiovascular system explain the rhythmic variations in the susceptibility of human beings to morbid and mortal events.

The foregoing results describing a cohort of 1063 patients recruited from 65 CCU located in Argentina and Uruguay who were admitted to the CCU within $24 \mathrm{~h}$ of the onset of symptoms of an acute MI, point out to the existence of two maxima in the incidence of MI, at the morning (mean value $=7.5 \% / \mathrm{h}$ between $08: 00$ and $12: 00 \mathrm{~h}$ ) and at the afternoon (mean value $=6 \% / \mathrm{h}$ between 16:00 and 20:00 h). A nadir in nocturnal MI incidence ( $1.3 \%$ /h between 03:00 and 07:00 h) and a secondary minimum at early afternoon (3.8 \%/h between 13:00 and 15:00 h) also occurred. The best fit curve (explaining ca. $85 \%$ of variance) was a $24 \mathrm{~h}$ cosinor (acrophase 19:00 h, accounting

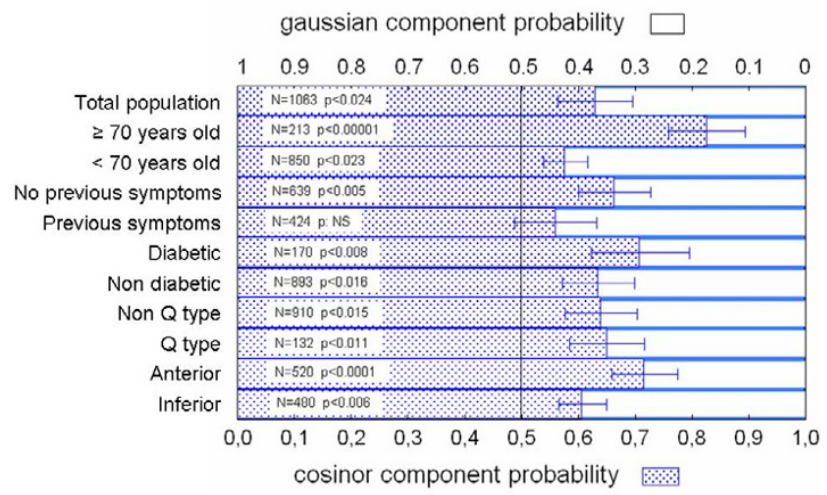

Figure 2

Probability of cosinor and gaussian components for total population and the excluding subgroups. Shown are the means \pm SEM. Statistical comparisons of means against 0.5 ( $50 \%$, see Methods for explanation) are shown. NS: non significant.

for $63 \%$ of variance) with a symmetrical gaussian "bell" (maximum at $\sim 10: 00 \mathrm{~h}$, accounting for $37 \%$ of variance).

A similar bimodal picture was observed for MI frequencies among different excluding subgroups (older or younger than 70 years; with or without previous symptoms; diabetics or non diabetics; Q wave- or non-Q wave-type MI; anterior or inferior MI location). Proportion between cosinor and gaussian probabilities was maintained among most subgroups except for older patients who tended to have more MI at the afternoon and for patients with previous symptoms, who had MI equally distributed between the morning and the afternoon maxima.

Following the proposed model, the population of patients in the present examined sample could be divided into those having more risk of $\mathrm{MI}$ in the morning (described by the gaussian function), and in those having more risk during the evening (described by the $24 \mathrm{~h}$ cosinor function). For subjects in the "cosinor distribution", the amplitude of oscillation $B$ resulted similar to the value of constant A (B/A ratio near unity), indicating a strong oscillation in MI episodes over the daily mean value of cosinor. Minimal (but not zero) MI incidence occurs at 07:00 $\mathrm{h}$, which slowly rises up to maximum at 19:00 $\mathrm{h}$ and then slowly declines toward the minimum at 07:00 $\mathrm{h}$.

For patients in the "gaussian distribution" a high incidence in MI was seen during the morning (maximum 10:00 h). For these patients MI begins to occur at 04:00 $\mathrm{h}$ and attains its maximum at 10:00 h with a fast decline towards 16:00 h. In this group MI episodes resulted virtually absent between 16:00 and 04:00 h. At the evening, the observed MI's belong only to the "cosinor group" while 


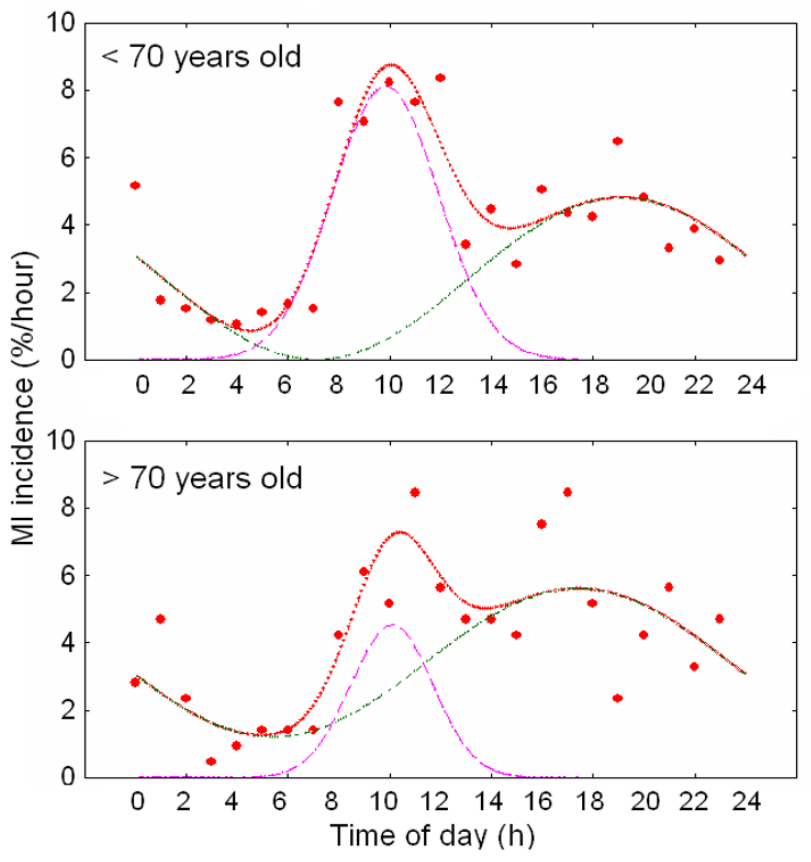

Figure 3

Circadian periodicity in $\mathrm{MI}$ incidence in patients younger and older than 70 years old. Probability density functions $(\% / \mathrm{h})$ for $\mathrm{MI}$ incidence are shown. Cosinor and gaussian components are depicted separately to illustrate the contribution of each parameter in fitting the function $y(t)$.

during morning hours, most of recorded MI's were suffered by the "gaussian group" plus a minor fraction (slowly increasing as time elapsed) of the "cosinor group".

Time dependence and width of peaks (described by phase lag of the cosinor or time of mean and SD of gaussian adjust) remained the same in the different excluding subgroups extracted from total population. Likewise, the fraction of population associated to each component (approximately $40 \%$ gaussian/60\% cosinor) was independent on the subgroup under consideration, except for patients older than 70 years and patients with previous symptoms. Indeed, older individuals appeared to double the chance to suffer a MI during the evening in comparison to morning hours ( $83 \%$ of the older patients suffered $\mathrm{MI}$ at evening vs. $17 \%$ in the morning). It should be noted that older and anterior infarct populations showed a significant increase in threshold above which the cosinor fitting is mounted. While the minimum for the different cosinors showed a mean value of $0.46 \pm 0.44 \% / \mathrm{h}(\mathrm{SD})$ the two populations mentioned showed mean values that differed for more than 2 SD over the mean in a one-tailed normal test. This could be interpreted as the occurrence of

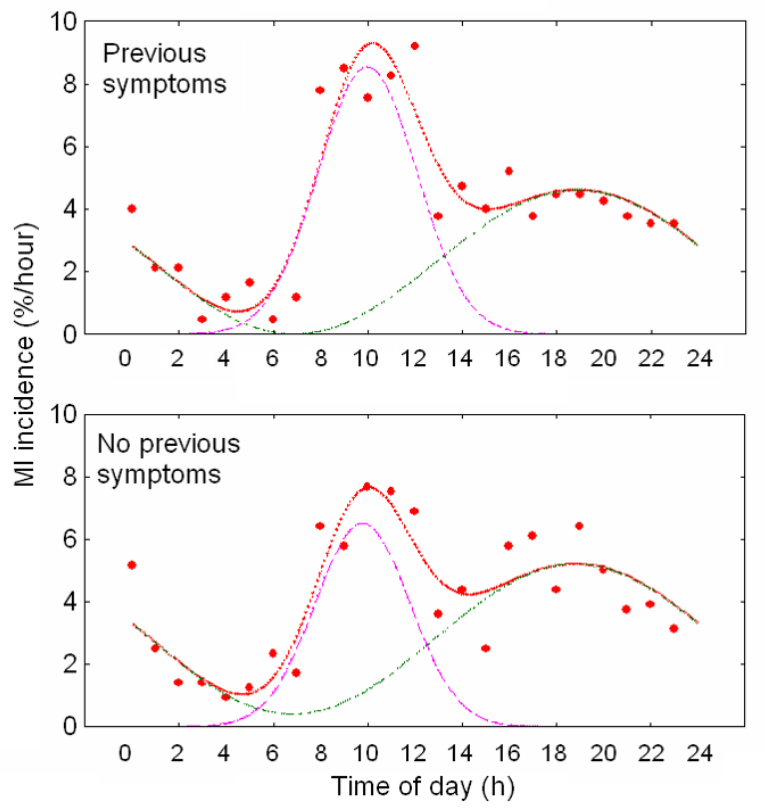

\section{Figure 4}

Circadian periodicity in $\mathrm{Ml}$ incidence in patients with or without previous symptomatology. Probability density functions $(\% / h)$ for $\mathrm{Ml}$ incidence are shown. Cosinor and gaussian components are depicted separately to illustrate the contribution of each parameter in fitting the function $y(t)$.

extra risk factor (s) whose probability maintains constant during the day.

The high susceptibility of this Argentine and Uruguayan population to show MI at the evening points out to the relevance of variations in the spectrum of cardiovascular disease between different regions of the world and ethnic groups [21-25]. Indeed, it has been suggested that environmental-genetic background, socio-economic, and customs could underlie ethnic disparities in cardiovascular risk factor profiles [30,31]. A recent study confirms the existence of ethnic disparities in cardiovascular risk prevalence [25].

The prevalence of afternoon episodes in the present sample as compared to other studies could be related to a different daytime schedule, exposure to light, meals or disparities in cardiovascular risk factors, e.g. smoking. A prolonged siesta, which is a common practice in the present Argentine and Uruguayan population, could be followed by an increase in heart rate and blood pressure as it happens after waking up in the morning [32], leading to an increase in cardiovascular events. Afternoon siesta, in fact, may act as a triggering factor for cardiac events, especially in elderly subjects $[33,34]$ 
Changes in heart rate, blood pressure, neural and humoral vasoactive factors and heart contractility are presumably involved in the increase of myocardial oxygen demand that predisposes to the ischemic attack [35-39]. In a recent paper we described the relationship between unstable angor and circadian periodicity of heart rate variability (HRV) in a group of patients hospitalized in the CCU. As compared to moderate angor patients, amplitude of $24 \mathrm{~h}$ variation of total power decreased in severely affected patients and the circadian oscillation of vagal control on the heart became free running [40]. To what extent free running of circadian rhythms in cardiovascular function accounts for the bimodal distribution of MI reported herein deserves to be further examined.

\section{Conclusion}

We are aware of the limitations of the present study. Determination of time of MI based on symptom onset could be subject to a bias, because it is possible that some people could have had symptoms for some hours and have called an ambulance later [41]. Taking this in consideration, the higher susceptibility of Argentine and Uruguayan patients to $\mathrm{MI}$ at the evening points out to the existence of significant variations in the spectrum of cardiovascular disease between different regions of the world and ethnic groups. Recognition of particular regional circadian patterns in myocardial ischemia is important in planning treatment strategies for patients with coronary artery disease to prevent the occurrence of sudden, catastrophic cardiac events.

\section{Competing interests}

The author(s) declare that they have no competing interests.

\section{Authors' contributions}

All authors have made substantial contributions to design of the analysis and the interpretation of data; and have been involved in drafting the article and revising it critically for important intellectual content; and have given final approval of the version to be published.

\section{Additional material}

\section{Additional File 1}

Curve fitting for MI probability density to MI incidence. Curve fitting for MI probability density to MI incidence for the total population of patients as for the excluding subgroups.

Click here for file

[http://www.biomedcentral.com/content/supplementary/14712261-6-1-S1.doc]

\section{Acknowledgements}

This work was supported by grants from the Agencia Nacional de Promoción Científica y Tecnológica, Argentina (PICT 14087) and the University of Buenos Aires (M 075). The original GEMICA study was supported by Roemmers Argentina Laboratory and was coordinated by GEMA (Grupo de Estudios Multicéntricos en Argentina): Coordinating Centers: Hospital Italiano, Hospital Ramos Mejía (Buenos Aires). Steering Committee: Mauricio Rosenbaum MD, Marcelo V. Elizari MD, Arturo Cagide MD, Luis Girotti MD, Justo Carbajales MD, José Martínez Martínez MD, Omar Scapín MD, Jorge Garguichevich MD, Sergio Hauad MD, César Belziti MD, Alfredo Sinisi MD. Safety and Monitoring Board: Carlos Fernández MD, Raúl Oliveri MD, Julio de la Riva MD, Jorge Trongé MD. The following medical centers and investigators participated in the GEMICA study: Buenos Aires: Hospital Italiano (Arturo Cagide, César Belziti, Mauricio Cohen, Federico Achilli); Hospital Ramos Mejía (Luis Girotti, Justo Carbajales, Néstor Covelli, Pablo Fiszlejder); Hospital de Clínicas José de San Martín (Eduardo Sampó, Ricardo Pérez de la Hoz, Malcolm Herrera); Hospital Pirovano (Julio Lázzari, Mario Fortunato, Mario Ciruzzi, Horacio Zylbersztejn); Instituto de Cardiología Hospital Español (Horacio Pomés Iparraguirre, Hugo Grancelli, Amalia Elizari); Hospital Santojanni (Noemí Prieto, David Ryba); Hospital Argerich (Alberto Ramos, Alfredo Piombo, Nilda Prado); Hospital Alemán (Gerardo Nau, José Gant López, Claudio Higa, Guillermo Migliaro); Hospital Israelita (Héctor Cercós, Hugo Torres, Saúl Soifer, Sandra Galarza, María Alejandra Luna); Sanatorio Julio Méndez (Daniel Zivano, Daniel Roitemburd, María Cabeza Fuente); Sanatorio Anchorena (Eduardo Mele, Néstor Pérez Baliño; Rafael lamevo); Hospital Churruca (Sergio Chekerdemián, Susana Lopardo, Daniel Ricón, Carlos Pasinato); Clínica Sagrada Familia (Fernando Sokn); Hospital Durand (Alberto Demartini, Edgardo Beck). Provincia de Buenos Aires: Hospital Eva Perón (Alfredo Sinisi, Francisco Gadaleta); Instituto de Cirugía de Haedo (Guillermo Alonso, Silvia Ferreyra Cantante, Mario Cameselle); Hospital de General Rodríguez (Mario Giaccone, Alberto Albino); Hospital de Merlo (Eduardo Quiroga, Rubén Sabureau); Clínica Santa Rita (Marcelo Dellatorre); Clínica Indarte (Marcos Litvak); Clínica Modelo de Moró (Johny Rosendy, Ana Salvatti, Juan Tacari); Hospital Posadas (Aristóbulo Balestrini, Antonio Norkus, Gustavo Romera); Clínica Coronel Suarez (Alberto Caccavo); Sanatorio Azul (Edgardo Capelli, Horacio Castro); Hospital Privado de la Comunidad de Mar del Plata (Luis Lembo, Alberto Becerra); Hospital San Felipe (Raúl Quijano); Centro de Salud Leónidas Lucero (José Santopinto, Gabriela Braccini, Gustavo De Salvo); Hospital Italiano de la Plata (Osvaldo Perrino, Luis Cartasegna); Clínica Río de la Plata (Eduardo Escudero, Oscar Pisano); Hospital San Martín de La Plata (Hugo Ruiz, Marcelo Uriarte); Hospital San Juan de Dios de la Plata (Daniel Corsiglia, Omar Rastelli, Marcelo Portis); Instituto Roberto Vacarezza (Jorge Albizzatti). Provincia de Córdoba: Instituto Modelo de Cardiologia (Daniel Boccardo, Marcelo Coll); Hospital Militar (Roberto Bastianelli); Sanatorio Allende (Julio Bono, Luis Guzmán); Instituto de Cardiología Hospital Italiano (Raúl Alasino, Ricardo Martelloto); Hospital Privado (Roberto Madohery). Provincia de Corrientes: Instituto de Cardiología J.F. Cabral (Reynaldo Badaracco, Eduardo Perna, Stella Maris Macín); Hospital Escuela José de San Martín (Carlos Sosa). Provincia de Chaco: CORDIS (Alejandro Ventura, José Woroszylo). Provincia de Entre Ríos: Instituto de Cardiología de Entre Ríos (Ubaldo lbarzábal, Dante Moine). Provincia de Mendoza: Hospital Lagomaggiore (Adolfo Gambarte, José Antonio Hidalgo, Jorge Piasentín). Provincia de Neuquén: Policlínico de Neuquén (Luis Otatti, Juan Rueda Rivas, Lucía Buffolo); Clínica Pasteur (Ricardo Moreno, Marcelo Chambó). Provincia de Río Negro: Clínica Central Villa Regina (Oscar López, Jorge Alvarez, Ricardo ludica). Provincia de Salta: Hospital San Bernardo (Carlos Cúneo); Instituto Médico (Jorge Sánchez, Carlos Biella). Provincia de Santa Fe: Hospital Cullen (Carlos Becker); Sanatorio San Gerónimo (Ricardo Fernández); Hospital Italiano de Rosario (José Luis Ramos, Laura Sanziani, Marcelo Menéndez); Hospital Español de Rosario (Jorge Garguichevich, Marcelo Cardona); Hospital Fer- 
roviario de Rosario (Guillermo Bembibre); Sanatorio UOM de Rosario (Germán Godoy); Sanatorio Plaza de Rosario (Antonio Gentile, Marcelo Marco); Sanatorio Castelli (Gladys de Aguirre). Provincia de San Juan: Hospital Marcial Quiroga (Adrian D'Ovidio). Provincia de Santiago del Estero: Instituto de Cardiología (Pablo Secco). Provincia de Tucumán: Hospital Padilla (Sergio Hauad); Sanatorio ADOS (Héctor Luciardi); Instituto de Cardiología (Ramiro Castellanos, Rubén Arévalo); Sanatorio Rivadavia (Eduardo Hasbani, Alberto Sabaj); Centro Modelo de Cardiología (Juan Muntaner); Sanatorio 9 de Julio (Enrique Alonso, Esteban Avila). República Oriental del Uruguay: Sociedad Española (Solvey Bentancourt); Hospital Evangélico (Pedro Amonte).

\section{References}

1. Pell S, D'alonzo CA: Acute myocardial infarction in a large industrial population: Report of a 6-year study of I,356 cases. JAMA 1963, I 85:83I-838.

2. Cohen MC, Rohtla KM, Lavery CE, Muller JE, Mittleman MA: Metaanalysis of the morning excess of acute myocardial infarction and sudden cardiac death. Am / Cardiol 1997, 79:15। 2-1516.

3. Muller JE, Ludmer PL, Willich SN, Tofler GH, Aylmer G, Klangos I, Stone PH: Circadian variation in the frequency of sudden cardiac death. Circulation 1987, 75: $131-138$.

4. Hjalmarson A, Gilpin EA, Nicod P, Dittrich H, Henning H, Engler R, Blacky AR, Smith SC Jr, Ricou F, Ross J Jr: Differing circadian patterns of symptom onset in subgroups of patients with acute myocardial infarction. Circulation 1989, 80:267-275

5. Willich SN, Levy D, Rocco MB, Tofler GH, Stone PH, Muller JE: Circadian variation in the incidence of sudden cardiac death in the Framingham Heart Study population. Am J Cardiol 1987 60:80I-806.

6. Lucente M, Rebuzzi AG, Lanza GA, Tamburi S, Cortellessa MC, Coppola E, lannarelli M, Manzoli U: Circadian variation of ventricular tachycardia in acute myocardial infarction. Am J Cardiol 1988 , 62:670-674.

7. Argentino C, Toni D, Rasura M, Violi F, Sacchetti ML, Allegretta A, Balsano F, Fieschi C: Circadian variation in the frequency of ischemic stroke. Stroke 1990, 21:387-389.

8. Ridker PM, Manson JE, Buring JE, Muller JE, Hennekens CH: Circadian variation of acute myocardial infarction and the effect of low-dose aspirin in a randomized trial of physicians. Circulation 1990, 82:897-902

9. Pepine $\mathrm{Cl}$ : Circadian variations in myocardial ischemia. Implications for management. JAMA I991, 265:386-390.

10. Levine RL, Pepe PE, Fromm RE Jr, Curka PA, Clark PA: Prospective evidence of a circadian rhythm for out-of-hospital cardiac arrests. JAMA 1992, 267:2935-2937.

II. Willich SN, Goldberg RJ, Maclure M, Perriello L, Muller JE: Increased onset of sudden cardiac death in the first three hours after awakening. Am J Cardiol 1992, 70:65-68.

12. Muller JE, Stone PH, Turi ZG, Rutherford JD, Czeisler CA, Parker C, Poole WK, Passamani E, Roberts R, Robertson T, et al: Circadian variation in the frequency of onset of acute myocardial infarction. N Engl J Med 1985, 3 | 3:13/5-|322

13. Peters RW, Zoble RG, Liebson PR, Pawitan Y, Brooks MM, Proschan $M$ : Identification of a secondary peak in myocardial infarction onset II to I 2 hours after awakening: the Cardiac Arrhythmia Suppression Trial (CAST) experience. J Am Coll Cardiol 1993, 22:998-1003.

14. Behar S, Halabi M, Reicher-Reiss H, Zion M, Kaplinsky E, Mandelzweig L, Goldbourt U: Circadian variation and possible external triggers of onset of myocardial infarction. SPRINT Study Group. Am J Med 1993, 94:395-400.

15. Manfredini R, Boari B, Bressan S, Gallerani M, Salmi R, Portaluppi F, Mehta $\mathrm{RH}$ : Influence of circadian rhythm on mortality after myocardial infarction: data from a prospective cohort of emergency calls. Am J Emerg Med 2004, 22:555-559.

16. Gallerani M, Portaluppi F, Maida G, Chieregato A, Calzolari F, Trapella $G$, Manfredini R: Circadian and circannual rhythmicity in the occurrence of subarachnoid hemorrhage. Stroke 1996, 27: $1793-1797$

17. Casetta I, Granieri E, Portaluppi F, Manfredini R: Circadian variability in hemorrhagic stroke. JAMA 2002, 287:|266-। 267.
18. Casetta I, Granieri E, Fallica E, la Cecilia O, Paolino E, Manfredini R: Patient demographic and clinical features and circadian variation in onset of ischemic stroke. Arch Neurol 2002, 59:48-53.

19. Manfredini R, Portaluppi F, Zamboni P, Salmi R, Gallerani M: Circadian variation in spontaneous rupture of abdominal aorta. Lancet 1999, 353:643-644.

20. Manfredini R, Gallerani M, Portaluppi F, Salmi R, Zamboni P, Fersin $C$ : Circadian variation in the onset of acute critical limb ischemia. Thromb Res 1998, 92:163-169.

21. Ounpuu S, Negassa A, Yusuf S: INTER-HEART: A global study of risk factors for acute myocardial infarction. Am Heart J 200I, |4|:7||-72|.

22. Mak KH, Kark JD, Chia KS, Tan C, Foong BH, Chew SK: Ethnic differences in utilization of invasive cardiac procedures and in long-term survival following acute myocardial infarction. Clin Cardiol 2004, 27:275-280

23. Mak KH, Kark JD, Chia KS, Sim LL, Foong BH, Ding ZP, Kam R, Chew SK: Ethnic variations in female vulnerability after an acute coronary event. Heart 2004, 90:62I-626.

24. Mak KH, Chia KS, Kark JD, Chua T, Tan C, Foong BH, Lim YL, Chew SK: Ethnic differences in acute myocardial infarction in Singapore. Eur Heart J 2003, 24:15I-160.

25. Lopez F, Lee KW, Marin F, Roldan V, Sogorb F, Caturla J, Lip GY. Are there ethnic differences in the circadian variation in onset of acute myocardial infarction? A comparison of 3 ethnic groups in Birmingham, UK and Alicante, Spain. Int / Cardiol 2005, 100: 15I-154.

26. Anand SS, Yusuf S, Vuksan V, Devanesen S, Teo KK, Montague PA Kelemen $L, Y i C$, Lonn E, Gerstein H, et al.: Differences in risk factors, atherosclerosis and cardiovascular disease between ethnic groups in Canada: the study of health assessment and risk in ethnic groups (SHARE). Indian Heart J 2000, 52:S35-S43.

27. Elizari MV, Martinez JM, Belziti C, Ciruzzi M, Perez dIH, Sinisi A, Carbajales J, Scapin O, Garguichevich J, Girotti L, et al:: Morbidity and mortality following early administration of amiodarone in acute myocardial infarction. GEMICA study investigators, GEMA Group, Buenos Aires, Argentina. Grupo de Estudios Multicentricos en Argentina. Eur Heart J 2000, 21 : 1 98-205.

28. Hastings MH, Reddy AB, Maywood ES: A clockwork web: circadian timing in brain and periphery, in health and disease. Nat Rev Neurosci 2003, 4:649-661.

29. Gachon F, Nagoshi E, Brown SA, Ripperger J, Schibler U: The mammalian circadian timing system: from gene expression to physiology. Chromosoma 2004, I I 3:103-1 I2.

30. Schaefer BM, Caracciolo V, Frishman WH, Charney P: Gender, ethnicity, and genes in cardiovascular disease. Part 2: implications for pharmacotherapy. Heart Dis 2003, 5:202-214.

31. Schaefer BM, Caracciolo V, Frishman WH, Charney P: Gender, ethnicity and genetics in cardiovascular disease: part I: Basic principles. Heart Dis 2003, 5: 129-I43.

32. Stergiou GS, Vemmos KN, Pliarchopoulou KM, Synetos AG, Roussias LG, Mountokalakis TD: Parallel morning and evening surge in stroke onset, blood pressure, and physical activity. Stroke 2002, 33: $1480-\mid 486$

33. Bursztyn M, Mekler J, Ben Ishay D: The siesta and ambulatory blood pressure: is waking up the same in the morning and afternoon? J Hum Hypertens 1996, 10:287-292.

34. Bursztyn M, Ginsberg G, Hammerman-Rozenberg R, Stessman J: The siesta in the elderly: risk factor for mortality? Arch Intern Med 1999, 159:1582-1586.

35. Fuster V, Steele PM, Chesebro JH: Role of platelets and thrombosis in coronary atherosclerotic disease and sudden death. J Am Coll Cardiol 1985, 5: 175B- I84B.

36. Jovicic $A$, Mandic S: Circadian variations of platelet aggregability and fibrinolytic activity in healthy subjects. Thromb Res 1991, 62:65-74

37. Quyyumi AA, Panza JA, Diodati JG, Lakatos E, Epstein SE: Circadian variation in ischemic threshold. A mechanism underlying the circadian variation in ischemic events. Circulation 1992, 86:22-28.

38. Talan MI, Engel BT: Morning increase in whole blood viscosity: a consequence of a homeostatic nocturnal haemodynamic pattern. Acta Physiol Scand 1993, 147: 179-183.

39. Feng DL, Tofler GH: Diurnal physiologic processes and circadian variation of acute myocardial infarction. J Cardiovasc Risk $1995,2: 494-498$. 
40. D'Negri CE, Marelich L, Vigo DE, Acunzo RS, Girotti L, Cardinali DP, Nicola-Siri L: Circadian periodicity of heart rate variability in hospitalized angor patients. Clin Autonom Res 2005, 15:223-232.

41. Willich SN, Linderer T, Wegscheider K, Leizorovicz A, Alamercery I, Schroder R: Increased morning incidence of myocardial infarction in the ISAM Study: absence with prior beta-adrenergic blockade. ISAM Study Group. Circulation 1989, 80:853-858.

\section{Pre-publication history}

The pre-publication history for this paper can be accessed here:

http://www.biomedcentral.com/1471-2261/6/1/prepub

Publish with Bio Med Central and every scientist can read your work free of charge

"BioMed Central will be the most significant development for disseminating the results of biomedical research in our lifetime. "

Sir Paul Nurse, Cancer Research UK

Your research papers will be:

- available free of charge to the entire biomedical community

- peer reviewed and published immediately upon acceptance

- cited in PubMed and archived on PubMed Central

- yours - you keep the copyright

Submit your manuscript here:

http://www.biomedcentral.com/info/publishing_adv.asp 